\title{
Enhancing the thermoelectric properties of single and double filled p-type skutterudites synthesized by an up-scaled ball-milling process
}

Article

Accepted Version

Creative Commons: Attribution-Noncommercial-No Derivative Works 4.0

Prado Gonjal, J., Vaqueiro, P., Nuttall, C., Potter, R. and Powell, A. V. (2017) Enhancing the thermoelectric properties of single and double filled p-type skutterudites synthesized by an up-scaled ball-milling process. Journal of Alloys and Compounds, 695. pp. 3598-3604. ISSN 0925-8388 doi: https://doi.org/10.1016/j.jallcom.2016.11.404 Available at https://centaur.reading.ac.uk/68315/

It is advisable to refer to the publisher's version if you intend to cite from the work. See Guidance on citing.

Published version at: http://dx.doi.org/10.1016/j.jallcom.2016.11.404

To link to this article DOI: http://dx.doi.org/10.1016/j.jallcom.2016.11.404

Publisher: Elsevier

All outputs in CentAUR are protected by Intellectual Property Rights law, including copyright law. Copyright and IPR is retained by the creators or other copyright holders. Terms and conditions for use of this material are defined in the End User Agreement. 


\section{www.reading.ac.uk/centaur}

\section{CentAUR}

Central Archive at the University of Reading

Reading's research outputs online 


\section{Accepted Manuscript}

Enhancing the thermoelectric properties of single and double filled $p$-type skutterudites synthesized by an up-scaled ball-milling process

Jesús Prado-Gonjal, Paz Vaqueiro, Chris Nuttall, Robert Potter, Anthony V. Powell

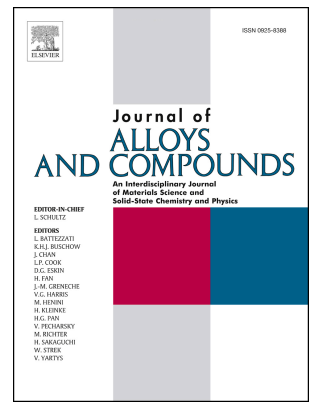

PII:

S0925-8388(16)33887-7

DOI:

10.1016/j.jallcom.2016.11.404

Reference: JALCOM 39901

To appear in: Journal of Alloys and Compounds

Received Date: 12 October 2016

Revised Date: 19 November 2016

Accepted Date: 29 November 2016

Please cite this article as: J. Prado-Gonjal, P. Vaqueiro, C. Nuttall, R. Potter, A.V. Powell, Enhancing the thermoelectric properties of single and double filled $p$-type skutterudites synthesized by an up-scaled ball-milling process, Journal of Alloys and Compounds (2016), doi: 10.1016/j.jallcom.2016.11.404.

This is a PDF file of an unedited manuscript that has been accepted for publication. As a service to our customers we are providing this early version of the manuscript. The manuscript will undergo copyediting, typesetting, and review of the resulting proof before it is published in its final form. Please note that during the production process errors may be discovered which could affect the content, and all legal disclaimers that apply to the journal pertain. 


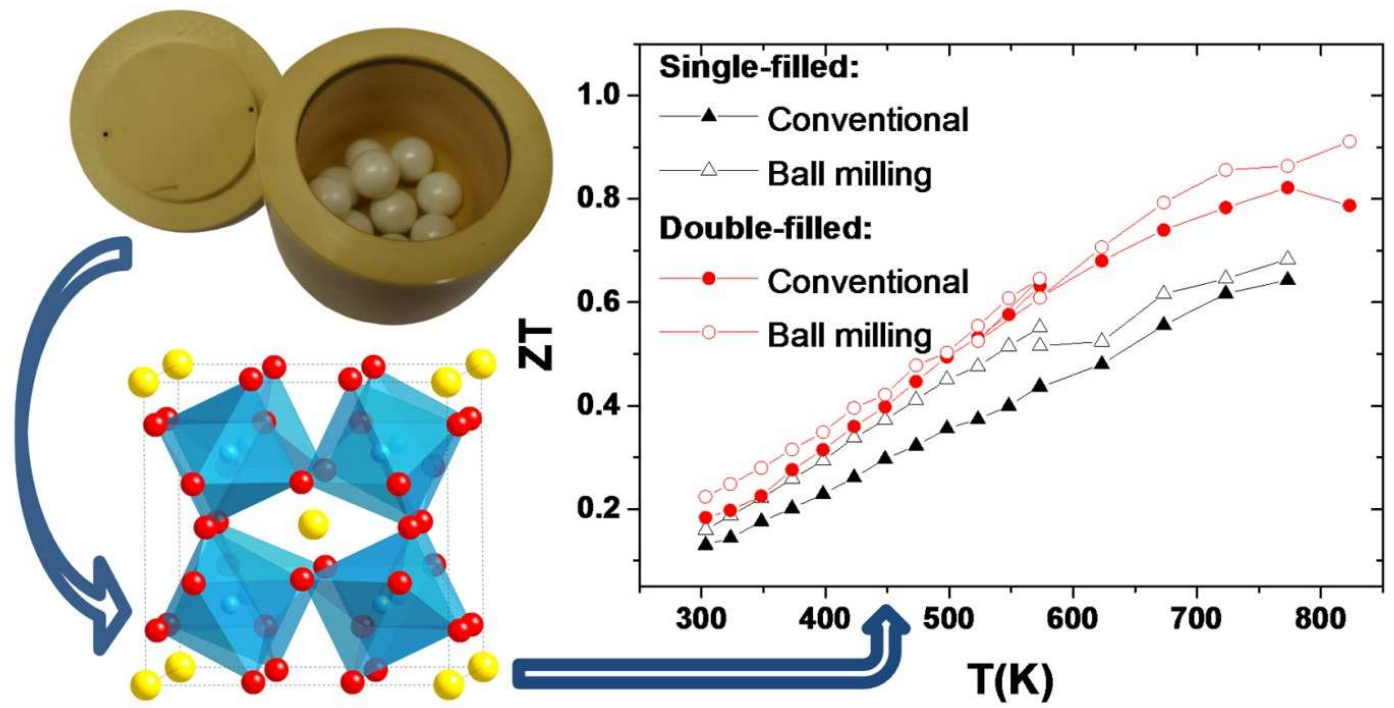




\title{
Enhancing the thermoelectric properties of single and double filled $p$-type skutterudites synthesized by an up-scaled ball-milling process
}

\author{
Jesús Prado-Gonjal, ${ }^{1}$ Paz Vaqueiro, ${ }^{1}$ Chris Nuttall, ${ }^{2}$ Robert Potter ${ }^{2}$ and Anthony V. \\ Powell $^{1 *}$ \\ 1 Department of Chemistry, University of Reading, RG6 6AD, Reading, UK \\ 2 Johnson Matthey Technology Centre, Blounts Court Road, RG4 9NH, Sonning Common, \\ UK \\ *a.v.powell@ reading.ac.uk.
}

\begin{abstract}
The single and double filled p-type skutterudites $\mathrm{Ce}_{0.8} \mathrm{Fe}_{3} \mathrm{CoSb}_{12}$ and $\mathrm{Ce}_{0.5} \mathrm{Yb}_{0.5} \mathrm{Fe}_{3.25} \mathrm{Co}_{0.75} \mathrm{Sb}_{12}$ have been prepared by mechanical alloying. This offers a rapid method for the preparation of skutterudites that could be scaled up for adoption at industrial level. The large-scale samples prepared by ball-milling exhibit enhanced figures of merit ZT, compared with materials prepared by conventional solid-state reaction. At room temperature ZT is increased by ca. $19 \%$ for both single and double filled skutterudites. Maximum figures of merit, $\mathrm{ZT}=0.68$ and $\mathrm{ZT}=0.93$ are attained for $\mathrm{Ce}_{0.8} \mathrm{Fe}_{3} \mathrm{CoSb}_{12}$ at $773 \mathrm{~K}$ and $\mathrm{Ce}_{0.5} \mathrm{Yb}_{0.5} \mathrm{Fe}_{3.25} \mathrm{Co}_{0.75} \mathrm{Sb}_{12}$ at $823 \mathrm{~K}$ respectively. The improvement in thermoelectric values at room temperature may be traced to a reduction in thermal conductivity in the ball-milled samples arising from the reduced grain size. The influence of the microstructure on the thermoelectric properties, together with the stability in air and the performance of the materials after several heating and cooling cycles has been studied and are detailed in this work. The densified samples prepared by ball-milling also show a higher resistance to oxidation, which starts at $694 \mathrm{~K}$ for $\mathrm{Ce}_{0.8} \mathrm{Fe}_{3} \mathrm{CoSb}_{12}$ and at $783 \mathrm{~K}$ for $\mathrm{Ce}_{0.5} \mathrm{Yb}_{0.5} \mathrm{Fe}_{3.25} \mathrm{Co}_{0.75} \mathrm{Sb}_{12}$.
\end{abstract}

\section{Keywords}

Thermoelectric Materials; Inorganic Materials; Intermetallics; Mechanical Alloying Electrical Transport; Heat Conduction 


\section{Introduction}

Thermoelectric (TE) materials are expected to play an important role in a global sustainable energy solution by facilitating reductions in fossil fuel consumption and optimisation of energy usage. The scientific challenge is to optimise the three key inter-dependent properties of the materials: Seebeck coefficient $(S)$, electrical $(\sigma)$ and thermal $(\kappa)$ conductivities, which determine the figure of merit $\left(\mathrm{ZT}=\mathrm{S}^{2} \sigma \mathrm{T} / \kappa\right)$ and the TE performance.[1, 2]

One approach to creating materials with high $\mathrm{ZT}$ values is to select a semiconductor with a large power factor $\left(\mathrm{PF}=\mathrm{S}^{2} \sigma\right)$ and minimize its thermal conductivity. Since $\kappa$ has electronic $\left(\kappa_{\mathrm{e}}\right)$ and lattice $\left(\kappa_{\mathrm{L}}\right)$ contributions, the strategy is to target reductions in $\kappa_{\mathrm{L}}$ without impairing the electron transport properties.[3] This is the approach adopted in skutterudites, which crystallise in a body-centred cubic structure (space group $\operatorname{Im} \overline{3}$ ) containing two $\mathrm{M}_{4} \mathrm{X}_{12}$ formula units and two large empty cages per unit cell.[4, 5]' The prototypical $\mathrm{CoSb}_{3}$ possesses a large power factor $\left(\mathrm{S}^{2} \sigma \approx 30 \mu \mathrm{W} \mathrm{cm}^{-1} \mathrm{~K}^{-2}\right)$ but the thermal conductivity is too high $\left(\kappa \approx 10 \mathrm{~W} \mathrm{~m}^{-1} \mathrm{~K}^{-1}\right.$ at $\left.298 \mathrm{~K}\right)$ to achieve high ZT.[6-8] Guest elements such as rare earth ions, often termed fillers, can partially occupy the cages (Figure 1). It has been proposed that localised "rattling" vibrations of the filler atoms lead to strong scattering of phonons, resulting in a marked reduction in lattice thermal conductivity.[9-11]

Scattering of heat-carrying phonons is maximised for those with frequencies close to the resonance frequency of the filler. Multiple fillers with different resonance frequencies promote scattering over a broader range of the phonon spectrum, reducing the lattice thermal conductivity over that of singly-filled systems.[12-15] However, filling skutterudites with multiple elements complicates the synthesis. To date, there have been a limited number of experimental reports on the synthesis of multiple- 
element-filled skutterudites and only modest improvements in TE performance have been achieved for $p$-type materials. [12, 16-19]

Singly and multiply-filled skutterudites are traditionally prepared by the melting-annealing method. This involves the reaction of the constituent elements by melting at high temperatures, followed by a lengthy annealing process to ensure the homogeneity of the final product. However, significant research efforts have been devoted to investigate new efficient ways to prepare materials by using alternative methodologies where the energy requirements for synthesis and reaction time are drastically reduced.[20-23] In this work, we present a fast synthetic procedure for the p-type materials, $\mathrm{Ce}_{0.8} \mathrm{Fe}_{3} \mathrm{CoSb}_{12}$ and $\mathrm{Ce}_{0.5} \mathrm{Yb}_{0.5} \mathrm{Fe}_{3.25} \mathrm{Co}_{0.75} \mathrm{Sb}_{12}$, using ball milling. These materials were selected to demonstrate the potential for scale up using ball milling techniques, as they have proven thermoelectric performance.[24-26] This technique uses mechanical energy to effect reaction. The fast collisions between the balls and powdered elements decreases the size of the reactant particles until active sites are created, facilitating the diffusion process, and causing reaction to take place.[27, 28] Furthermore, this methodology allows the preparation of large amounts of sample (> $60 \mathrm{~g}$ per batch at the laboratory scale) and is potentially scalable for large-scale industrial production of skutterudite materials. Moreover, the considerable reduction in the particle size of the synthesized products improves the sintering of the resulting nanopowders, which is beneficial in obtaining a dense bulk material by hot-pressing or alternative sintering process.

\section{Experimental}

\subsection{Synthetic procedures}

A $\mathrm{Ce}_{0.8} \mathrm{Fe}_{3} \mathrm{CoSb}_{12}$ single-filled skutterudite and a $\mathrm{Ce}_{0.5} \mathrm{Yb}_{0.5} \mathrm{Fe}_{3.25} \mathrm{Co}_{0.75} \mathrm{Sb}_{12}$ doublefilled skutterudite were synthesised by ball milling stoichiometric amounts of Ce (Alfa Aesar, 99.8\% ingot), Yb (Alfa Aesar, 99.9\% ingot), Fe (Aldrich, 99.9+\% powder), Co 
(Alfa Aesar, 99.8\% powder) and Sb (Alfa Aesar, 99.5\% powder). The appropriate amounts of the elements were loaded together with $13 \mathrm{ZrO}_{2}$ balls (20 mm diameter) into a $250 \mathrm{ml} \mathrm{ZrO}_{2}$ grinding vessel, equipped with a gas-tight lid, inside an argonfilled glove-box. A powder to balls ratio of 1:5 by weight was used and the filling level of the grinding bowl (chemicals and balls) was ca. $30 \%$. The grinding vessel was loaded into a Fritsch FP5 Planetary Ball Mill. Grinding was carried out at $400 \mathrm{rpm}$ in 15 min interval steps with a change of direction, for $10 \mathrm{~h}$.

In order to study the influence of ball-milling on the TE properties, reference samples of $\mathrm{Ce}_{0.8} \mathrm{Fe}_{3} \mathrm{CoSb}_{12}$ and $\mathrm{Ce}_{0.5} \mathrm{Yb}_{0.5} \mathrm{Fe}_{3.25} \mathrm{Co}_{0.75} \mathrm{Sb}_{12}$ were synthesized using the meltingannealing route. The reaction conditions used were those previously described by García-Cañadas et al. [24] and Ballikaya et al. [25] for the single and the double filled skutterudites, respectively. The melting-annealing synthesis in a sealed silica tube is restricted in scale, typically generating 5-7 $\mathrm{g}$ of the product material. By contrast, the ball-milling process enables $60 \mathrm{~g}$ of skutterudite to be produced in a single step, whilst reducing the synthesis time from 1-2 weeks to $10 \mathrm{~h}$.

The synthesized materials were consolidated by hot pressing. Powders were loaded into a graphite mould with tungsten carbide dies and hot-pressed at $873 \mathrm{~K}$ for 30 minutes, at a pressure of $100 \mathrm{MPa}$, under a flowing nitrogen atmosphere. It should be noted that ball-milled samples must be kept under an inert gas when transferring from the glove box to the hot press. The skutterudite nanoparticles can ignite when in contact with air, although samples are stable following consolidation.

The densities of the consolidated pellets were measured using an Archimedes balance ADAM PW184. All densified pellets from ball-milling powder were found to have densities above $98 \%$ of the crystallographic values of $7.8 \mathrm{~g} \mathrm{~cm}^{-3}\left(\mathrm{Ce}_{0.8} \mathrm{Fe}_{3} \mathrm{CoSb}_{12}\right)$ and $8.0 \mathrm{~g} \mathrm{~cm}^{-3}\left(\mathrm{Ce}_{0.5} \mathrm{Yb}_{0.5} \mathrm{Fe}_{3.25} \mathrm{Co}_{0.75} \mathrm{Sb}_{12}\right)$. 


\subsection{Powder X-Ray diffraction and Rietveld refinements}

Powder X-ray diffraction (XRD) data for all samples were collected using a Bruker D8 Advance Powder X-ray diffractometer, operating with $\mathrm{Ge}$ monochromated $\mathrm{Cu} \mathrm{K}_{\alpha 1}$ radiation $(\lambda=1.54046 \AA)$ and fitted with a LynxEye detector. Data were collected over the angular range $5 \leq 2 \theta /^{\circ} \leq 120$ for 6 hours. For the samples prepared by ball-milling, a sample holder for air sensitive samples was used, in which the powder is placed between two layers of Kapton film.

Structural refinements were carried out using the Rietveld method implemented in the FullProf software package.[29] The peak shape was described using a Thompson-CoxHastings pseudo-Voigt profile function. The background was fitted using linear interpolation. The zero point shift, lattice parameter, fractional atomic coordinates and isotropic thermal displacement parameters were then refined.

\subsection{SEM-EDS}

Scanning Electron Microscopy (SEM) studies were carried out on the surface of sintered pellets using a FEI Quanta FEG 600 Environmental Scanning Electron Microscope, operating at a voltage of $20 \mathrm{kV}$ under high vacuum. The microscope is fitted with an X-ray Energy Dispersive Spectroscopy (XEDS) analyser. XEDS analysis was performed on both powder and pellets sampling 5 different areas of each image in order to determine the average composition and gauge the level of homogeneity.

\subsection{Thermogravimetric analysis}


A TA-Q600SDT TGA instrument was used to investigate the thermal stability of $c a .40 \mathrm{mg}$ of skutterudite powder and of a fragment pellet as a function of temperature in air. The samples were heated from room temperature to $873 \mathrm{~K}$, with a $5 \mathrm{~K} \mathrm{~min}^{-1}$ ramp rate.

\subsection{Electrical and thermal transport measurements}

The electrical resistivity $(\rho)$ and Seebeck coefficient (S) were measured simultaneously for a consolidated pellet using a Linseis LSR-3 instrument over the temperature range $300 \leq T / K \leq$ 823 , under a temperature gradient of $50 \mathrm{~K}$, using an applied current of $100 \mathrm{~mA}$ and a partial pressure of He. The sample was mounted on Pt electrodes and 2 thermocouple probes were attached on one side. Five heating and cooling cycles were carried out to investigate the performance of the materials on cycling. The chamber was evacuated and filled with a partial pressure of He between each measurement.

A Netzsch LFA 447 NanoFlash instrument was employed to measure the thermal diffusivity $(\alpha)$ and the heat capacity $\left(C_{p}\right)$ of the samples over a temperature range of $300 \leq T / \mathrm{K} \leq 573$ in $25 \mathrm{~K}$ steps. Higher Temperature measurements $(573 \leq T / \mathrm{K} \leq 823 \mathrm{~K})$ in $50 \mathrm{~K}$ steps were performed using an Anter Flashline 3000 instrument. The consolidated samples have a diameter of $12.7 \mathrm{~mm}$ and a thickness of $c a .2 \mathrm{~mm}$. In order to maximise the heat absorption, a graphite coating was applied to the surface of the pellet. The thermal conductivity $(\kappa)$ is

calculated using $\kappa=\alpha C_{\mathrm{p}} \rho$, where $\rho$ is the sample density. A reference material, Pyroceram ${ }^{\mathrm{TM}}$ 9606, was used as a reference for the determination of the heat capacity of the samples. Cowan's model [30] with a pulse correction was applied to calculate $\alpha$. The electronic $\left(\kappa_{\mathrm{e}}\right)$ and lattice $\left(\kappa_{\mathrm{L}}\right)$ contributions of the thermal conductivity were estimated using the electrical conductivity data in conjunction with the Wiedemann-Franz law with a Lorenz constant of $2.45 \times 10^{-8} \mathrm{~W} \Omega \mathrm{K}^{-2} \cdot[31]$ 


\section{Results and discussion}

\subsection{Structural and microstructural characterization}

Powder X-ray diffraction data for the as-prepared ball-milled samples and for the consolidated ball-milled samples (Figure 2) indicate that a skutterudite phase has been formed. Comparison with data collected on the reference samples (ESI) indicates that the samples prepared by ball-milling are of higher purity than the conventional samples, for which small amounts of secondary phases, including $\mathrm{Sb}$ and $\mathrm{Yb}_{2} \mathrm{O}_{3}$, are present. The nanometric size of the ball-milled powders is evidenced by the significant diffraction line broadening. Average crystallite sizes were calculated from the full width at half maximum of

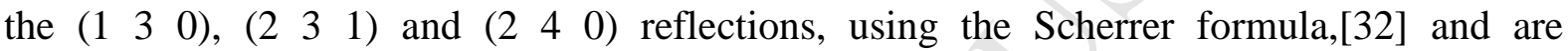
summarized in Table 1. Crystallite sizes for the ball-milled samples are significantly smaller than those for the conventionally-prepared samples. In both cases, the crystallite size increases with hot pressing. A similar particle size distribution [33], has been observed in skutterudites of general formula $\mathrm{DD}_{\mathrm{y}}\left(\mathrm{Fe}_{1-\mathrm{x}} \mathrm{Co}_{\mathrm{x}}\right)_{4} \mathrm{Sb}_{12}$ (DD: didymium $=$ mixture of $\mathrm{Pr}$ and $\mathrm{Nd}$ ), with a crystallite size of $c a .100 \mathrm{~nm}$, synthesized by ball-milling.

As illustrated in Figure 3, Rietveld refinements using the filled skutterudite crystal structure [34] for the initial structural model, yielded satisfactory fits for ground ball-milled pellets. In the case of the single-filled skutterudite, trace amounts of $\mathrm{Sb}(\mathrm{ca} .2 \%)$ is present as a secondary phase. There is no evidence of impurity phases in the double-filled skutterudite. The lattice parameters are in good agreement with those previously reported for $\mathrm{Ce}_{0.8} \mathrm{Fe}_{3} \mathrm{CoSb}_{12},[34]$ as well as with those for the reference samples. Refinement of the site occupancy factors did not substantially improve the fit and hence site occupancy factors were fixed to their nominal values. Table 2 summarizes the results of the structural analysis for ball-milled samples, while results for the conventionally-prepared samples are included in the ESI. 
In all cases, SEM micrographs of the consolidated pellets (Figure 4) show a dense microstructure, void-free and with a relatively uniform grain size. The grains are smaller for the samples prepared by ball milling (Fig $4 \mathrm{a}$ and $4 \mathrm{c}$ ) than for those prepared by conventional synthesis (Fig. 4b and 4d). The grain size distribution is also narrower for the ball-milled samples than for the conventionally-prepared samples. The chemical composition determined by XEDS (ESI), summarized in Table 3, is in good agreement with the expected values based on the initial stoichiometry of the reaction mixtures.

\subsection{Stability in air - Thermogravimetric analysis}

Thermogravimetric data were collected in an atmosphere of air, in order to determine the stability of the materials and the onset of oxidation, under the conditions likely to be found in thermoelectric applications. As described in the experimental section, the as-prepared ballmilled nanoparticles can ignite in contact with air and hence it was not possible to carry out TGA analysis on the powder prepared by ball milling. Figure 5 shows the TGA curves for consolidated samples prepared by conventional and ball milling methods, and for the powders prepared by the conventional method. Upon heating, there is an increase in weight which indicates the onset of oxidation.

The oxidation of the pellets starts at higher temperatures than for the powder, indicating the legs in a thermoelectric module would be more stable than the as-prepared powder. The onset of oxidation occurs at $495 \mathrm{~K}$ for $\mathrm{Ce}_{0.8} \mathrm{Fe}_{3} \mathrm{CoSb}_{12}$ and at $623 \mathrm{~K}$ for the $\mathrm{Ce}_{0.5} \mathrm{Yb}_{0.5} \mathrm{Fe}_{3.25} \mathrm{Co}_{0.75} \mathrm{Sb}_{12}$ powder prepared by the melting-annealing method. It has been suggested that Fe-Sb-based skutterudites are oxidized more easily than the Co-Sb-based congeners and that the activation energy for oxidation of the former is lower.[35, 36] However, the impact of the rare-earth filler ions has not been examined extensively. Our data 
suggest that $\mathrm{Yb}$ stabilises the material with respect to oxidation. This may be related to the slight decrease in electropositive character across the rare-earth series.

For the $\mathrm{Ce}_{0.8} \mathrm{Fe}_{3} \mathrm{CoSb}_{12}$ pellet, oxidation begins at $593 \mathrm{~K}$ for the conventional sample and at $694 \mathrm{~K}$ for the ball-milled pellet, respectively. In the case of the double-filled skutterudite pellets, the thermal stability is higher, with oxidation taking place at $646 \mathrm{~K}$ (conventionally prepared sample) and $783 \mathrm{~K}$ (ball milled sample). In all cases, the ball-milled pellets have an improved thermal stability. This difference in the onset of oxidation for samples prepared by different methods may be related to the microstructure of the samples. To the best of our knowledge, this is the first time that this effect has been observed in skutterudite. As observed in the SEM micrographs, the samples prepared by ball-milling present a more regular surface, which contains more grain boundaries. XRD patterns after heating indicate the formation of oxides of the constituent elements $\left(\mathrm{FeSbO}_{4}, \mathrm{CoSb}_{2} \mathrm{O}_{6}, \mathrm{Sb}_{2} \mathrm{O}_{4}, \mathrm{Yb}_{3} \mathrm{O}_{4}, \mathrm{CeO}\right)$.

\subsection{Thermoelectric properties}

Figure 6 shows the Seebeck, resistivity and the power factor data $\left(S^{2} \sigma\right)$ for the single- and double-filled skutterudites prepared using different methods. The Seebeck coefficient is positive in all cases, indicating that the dominant charge carriers are holes ( $p$-type behaviour). $\mathrm{S}$ increases with temperature, reaching a maximum at $c a .800 \mathrm{~K}$ for all samples. The magnitude of the Seebeck coefficient is consistent with the literature value for the conventionally synthesised $\mathrm{Ce}_{0.5} \mathrm{Yb}_{0.5} \mathrm{Fe}_{3.25} \mathrm{Co}_{0.75} \mathrm{Sb}_{12}\left(\mathrm{~S} \approx 160 \mu \mathrm{V} \mathrm{K}{ }^{-1}\right.$ at $\left.800 \mathrm{~K}\right){ }^{24}$ whilst that for $\mathrm{Ce}_{0.8} \mathrm{Fe}_{3} \mathrm{CoSb}_{12}$ is slightly higher $\left(\mathrm{S} \approx 125 \mu \mathrm{V} \mathrm{K}{ }^{-1}\right.$ at $600 \mathrm{~K}$ against $110 \mu \mathrm{V} \mathrm{K}^{-1}$ at $\left.600 \mathrm{~K}\right)$ $[24,37,38]$. The number of charge carriers has been estimated from the linear part of $S(\mathrm{~T})$ (300 - $600 \mathrm{~K})$ using Mott's formula.[39, 40] The values obtained are in good agreement with the literature, and are presented in Table 4.[25, 41, 42] 
The electrical resistivity of the samples decreases slightly with decreasing temperature: a behaviour reminiscent of a metal. The resistivity of the ball-milled $\mathrm{Ce}_{0.8} \mathrm{Fe}_{3} \mathrm{CoSb}_{12}$ is $c a .12$ $\%$ higher than that of the conventionally prepared sample at room temperature. However, this is accompanied by an increase of $c a .15 \%$ in the Seebeck coefficient. As a result, the changes in electron-transport properties compensate one another, such that similar power factors are observed for both single and multiple-filled skutterudites. The power factor of $\mathrm{Ce}_{0.5} \mathrm{Yb}_{0.5} \mathrm{Fe}_{3.25} \mathrm{Co}_{0.75} \mathrm{Sb}_{12}$ is ca. $14 \%$ larger than for $\mathrm{Ce}_{0.8} \mathrm{Fe}_{3} \mathrm{CoSb}_{12}$.

The total thermal conductivity of the samples increases slightly with increasing temperature (Figure 7). The discontinuity in the measurements at $573 \mathrm{~K}(<7 \%)$ is due to discrepancies between the two instruments (LFA 447 NanoFlash and Anter Flashline 3000) used to measure thermal diffusivity in the different temperature ranges. The rare earth atoms located in the voids have a significant effect on phonon propagation, causing a decrease of $c a .80 \%$ in the total thermal conductivity at room temperature, compared to the archetypical $\mathrm{CoSb}_{3}$. The samples synthesised by ball milling exhibit a significantly lower thermal conductivity at room temperature than those prepared by the melting-annealing method: a $12 \%$ and $14 \%$ reduction being observed for $\mathrm{Ce}_{0.8} \mathrm{Fe}_{3} \mathrm{CoSb}_{12}$ and $\mathrm{Ce}_{0.5} \mathrm{Yb}_{0.5} \mathrm{Fe}_{3.25} \mathrm{Co}_{0.75} \mathrm{Sb}_{12}$, respectively. This improvement in the thermal transport properties is related to the influence of the interfaces in nanostructured phases, which scatter phonons with mean free paths larger than the interface spacing, producing a reduction in the lattice thermal conductivity.[43] This is demonstrated in Figure 7 which shows that the lattice contribution of the thermal conductivity for both ball-milled samples is much lower than for the reference samples (46\% and $45 \%$ decrease of $\kappa_{L}$ for $\mathrm{Ce}_{0.8} \mathrm{Fe}_{3} \mathrm{CoSb}_{12}$ and $\mathrm{Ce}_{0.5} \mathrm{Yb}_{0.5} \mathrm{Fe}_{3.25} \mathrm{Co}_{0.75} \mathrm{Sb}_{12}$, respectively). Above $500 \mathrm{~K}$, the reduction in thermal conductivity is less marked for the ball-milled double filled skutterudite, with an improvement of $c a .3 \%$, a value that is within the likely experimental error. The maintenance of the power factor for both single and multiple filled skutterudites together with 
the significant reduction in thermal conductivity, results in an increase in the figure of merit, $\mathrm{ZT}$, (Figure 8). In the case of $\mathrm{Ce}_{0.8} \mathrm{Fe}_{3} \mathrm{CoSb}_{12}$ the enhancement in $\mathrm{ZT}$ is $c a .6 \%$ whilst that of $\mathrm{Ce}_{0.5} \mathrm{Yb}_{0.5} \mathrm{Fe}_{3.25} \mathrm{Co}_{0.75} \mathrm{Sb}_{12}$ is $c a$. $14 \%$. The resulting figures of merit, ZT, for the single and double-filled skutterudites are $0.68(773 \mathrm{~K})$ and $0.93(823 \mathrm{~K})$, respectively. A summary of the thermoelectric properties of the samples investigated is presented in Table 5.

The evaluation of the thermal cyclability, over the temperature range $300 \leq \mathrm{T} / \mathrm{K} \leq 813$, of these materials was carried out for the sample with the highest ZT: $\mathrm{Ce}_{0.5} \mathrm{Yb}_{0.5} \mathrm{Fe}_{3.25} \mathrm{Co}_{0.75} \mathrm{Sb}_{12}$ prepared by ball milling. It was found that the TE performance is reproducible after 5 heating-cooling cycles. The additional transport property data are included in the ESI.

The figure of merit ZT obtained for the single filled skutterudite is close to the best values reported for single-filled skutterudites. Sales et al.[10] measured ZT $=0.8$ at $750 \mathrm{~K}$ for $\mathrm{LaFe}_{3} \mathrm{CoSb}_{12}$, whilst similar performance was obtained for $\mathrm{Ce}_{0.12} \mathrm{Fe}_{0.71} \mathrm{Co}_{3.29} \mathrm{Sb}_{12}$ by Tang et al.[44]. Zhou et al.[17] have reported ZT $=0.99$ at $700 \mathrm{~K}$ in the double-filled skutterudite $\mathrm{Yb}_{0.25} \mathrm{La}_{0.60} \mathrm{Fe}_{2.7} \mathrm{Co}_{1.3} \mathrm{Sb}_{12}$, whilst in a few cases, higher figures of merit have been obtained for double filled skutterudites., including $\mathrm{DD}_{0.65} \mathrm{Fe}_{3} \mathrm{CoSb}_{12}(\mathrm{ZT}=1.2 \text { at } 800 \mathrm{~K})^{[19]}$ and $\mathrm{DD}_{0.76} \mathrm{Fe}_{3.4} \mathrm{Ni}_{0.6} \mathrm{Sb}_{12}(\mathrm{ZT}=1.2$ at $800 \mathrm{~K}),[45]$ where DD refers to a mixture of Pr and $\mathrm{Nd}$.

Recently, commercially-produced skutterudite materials, with high ZT values, came onto the market supplied by Treibacher Industrie AG. The commercial $p$-type material exhibits a maximum of $\mathrm{ZT}=1.0 \pm 0.1,[33]$ similar to the double-filled skutterudite reported here. However the preparation of this material appears to necessitate the use of the melt quench annealing technique [46]. We believe the notable finding of the present work is the demonstration that is possible to scale up the preparation by ball milling and simultaneously reduce synthesis times of both single and double filled skutterudites, whilst achieving a level of performance comparable with that of materials prepared by conventional methods. 


\section{Conclusions}

In the present study we have successfully prepared single and double-filled skutterudites using a ball-milling process. This methodology offers a straightforward single step process that readily lends itself to scale-up. The materials prepared, $\mathrm{Ce}_{0.8} \mathrm{Fe}_{3} \mathrm{CoSb}_{12}$ and $\mathrm{Ce}_{0.5} \mathrm{Yb}_{0.5} \mathrm{Fe}_{3.25} \mathrm{Co}_{0.75} \mathrm{Sb}_{12}$, exhibit an enhanced thermoelectric performance, when compared to the conventionally prepared samples, with figures of merit, $\mathrm{ZT}=0.68$ for $\mathrm{Ce}_{0.8} \mathrm{Fe}_{3} \mathrm{CoSb}_{12}$ at $773 \mathrm{~K}$ and $\mathrm{ZT}=0.93$ for $\mathrm{Ce}_{0.5} \mathrm{Yb}_{0.5} \mathrm{Fe}_{3.25} \mathrm{Co}_{0.75} \mathrm{Sb}_{12}$ at $823 \mathrm{~K}$ being achieved. This improvement is due to a reduction in the lattice thermal conductivity, which may be associated with the reduction in grain-size and hence increase interface scattering as a result of ball milling. Furthermore, the densified samples prepared by ball-milling show a higher resistance to oxidation. The procedure detailed in this paper may be adaptable for large scale industrial production of air sensitive skutterudites.

\section{Acknowledgements}

The authors wish to thank the UK Engineering and Physical Sciences Council (EP/K019767/1) for financial support and The University of Reading for access to the Chemical Analysis Facility for powder X-ray diffraction and Thermogravimetric Analysis.

\section{References}

[1] G.J. Snyder, E.S. Toberer, Nat Mater, 7 (2008) 105-114.

[2] C. Wood, Rep Prog Phys, 51 (1988) 459.

[3] S. Ballikaya, H. Chi, J.R. Salvador, C. Uher, J Mater Chem A, 1 (2013) 12478-12484. 
[4] J.P. Fleurial, T. Caillat, A. Borshchevsky, AIP Conf Proc, 316 (1994) 40-44.

[5] J.R. Sootsman, D.Y. Chung, M.G. Kanatzidis, Angew Chem Int Edit, 48 (2009) 8616-8639.

[6] J.W. Sharp, E.C. Jones, R.K. Williams, P.M. Martin, B.C. Sales, J Appl Phys, 78 (1995) 10131018.

[7] M.S. Toprak, C. Stiewe, D. Platzek, S. Williams, L. Bertini, E. Müller, C. Gatti, Y. Zhang, M. Rowe, M. Muhammed, Adv Funct Mater, 14 (2004) 1189-1196.

[8] H. Luo, J.W. Krizan, L. Muechler, N. Haldolaarachchige, T. Klimczuk, W. Xie, M.K. Fuccillo, C. Felser, R.J. Cava, Nat Commun, 6 (2015).

[9] K. Kurosaki, G. Li, Y. Ohishi, H. Muta, S. Yamanaka, Front Chem, 2 (2014) 84.

[10] B. Sales, D. Mandrus, R.K. Williams, Science, 272 (1996) 1325-1328.

[11] M. Rull-Bravo, A. Moure, J. Fernandez, M. Martín-González, RSC Adv, 5 (2015) 41653-41667.

[12] X. Shi, J. Salvador, J. Yang, H. Wang, J. Electron. Mater., 38 (2009) 930-933.

[13] J. Yang, W. Zhang, S.Q. Bai, Z. Mei, L.D. Chen, Appl. Phys. Lett., 90 (2007) 192111.

[14] X. Tang, H. LI, Q. Zhang, M. Niino, T. Goto, J. Appl. Phys, 100 (2006) 123702.

[15] W.Y. Zhao, C.L. Dong, P. Wei, W. Guan, L.S. Liu, P.C. Zhai, X.F. Tang, Q.J. Zhang, J. Appl. Phys, 102 (2007) 113708.

[16] X. Shi, J. Yang, J.R. Salvador, M. Chi, J.Y. Cho, H. Wang, S. Bai, J. Yang, W. Zhang, L. Chen, J. Am. Chem. Soc, 133 (2011) 7837-7846.

[17] L. Zhou, P. Qiu, C. Uher, X. Shi, L. Chen, Intermetallics, 32 (2013) 209-213.

[18] G. Rogl, A. Grytsiv, P. Heinrich, E. Bauer, P. Kumar, N. Peranio, O. Eibl, J. Horky, M. Zehetbauer, P. Rogl, Acta Mater, 91 (2015) 227-238.

[19] G. Rogl, A. Grytsiv, P. Rogl, E. Bauer, M. Zehetbauer, Intermetallics, 19 (2011) 546-555.

[20] L. Zhang, A. Grytsiv, M. Kerber, P. Rogl, E. Bauer, M.J. Zehetbauer, J. Wosik, G.E. Nauer, J. Alloy Compd, 481 (2009) 106-115. 
[21] J. Yang, Y. Chen, J. Peng, X. Song, W. Zhu, J. Su, R. Chen, J. Alloy Compd., 375 (2004) 229232.

[22] Q. Jie, H. Wang, W. Liu, H. Wang, G. Chen, Z. Ren, Phys. Chem. Chem. Phys., 15 (2013) 68096816.

[23] A. Ioannidou, M. Rull, M. Martin-Gonzalez, A. Moure, A. Jacquot, D. Niarchos, J. Electron. Mater, 43 (2014) 2637-2643.

[24] J. García-Cañadas, A.V. Powell, A. Kaltzoglou, P. Vaqueiro, G. Min, J. Electron. Mater., 42 (2012) 1369-1374.

[25] S. Ballikaya, N. Uzar, S. Yildirim, H. Chi, X. Su, G. Tan, X. Tang, C. Uher, J. Electron. Mater., 42 (2012) 1622-1627.

[26] B.C. Sales, D. Mandrus, B.C. Chakoumakos, V. Keppens, J.R. Thompson, Physical Review B, 56 (1997) 15081-15089.

[27] C. Suryanarayana, Prog Mater Sci, 46 (2001) 1-184.

[28] V. Boldyrev, Proceedings of Indian National Science Academy, 52 (1986) 400-417.

[29] J. Rodriguez-Carvajal, Satellite Meeting on Powder diffraction of the XV Congress of the IUCr, 127 (1990).

[30] R.D. Cowan, J. Appl. Phys, 34 (1963) 926-927.

[31] D.M. Rowe, CRC Handbook of Thermoelectrics, CRC Press, 1995.

[32] A.L. Patterson, Phys. Rev., 56 (1939) 978-982.

[33] G. Rogl, A. Grytsiv, P. Rogl, E. Bauer, M. Hochenhofer, R. Anbalagan, R.C. Mallik, E. Schafler, Acta Materialia, 76 (2014) 434-448.

[34] D. Bérardan, C. Godart, E. Alleno, E. Leroy, P. Rogl, J Alloy Compd, 350 (2003) 30-35.

[35] D.-K. Shin, I.-H. Kim, K.-H. Park, S. Lee, W.-S. Seo, J. Electron. Mater., 44 (2015) 1858-1863.

[36] X. Xia, P. Qiu, X. Huang, S. Wan, Y. Qiu, X. Li, L. Chen, J. Electron. Mater., 43 (2014) 16391644. 
[37] B.C. Sales, D. Mandrus, B.C. Chakoumakos, V. Keppens, J.R. Thompson, Phys. Rev. B, 56 (1997) 15081-15089.

[38] P.F. Qiu, J. Yang, R.H. Liu, X. Shi, X.Y. Huang, G.J. Snyder, W. Zhang, L.D. Chen, J. Appl. Phys, 109 (2011) 063713.

[39] G. Rogl, A. Grytsiv, N. Melnychenko-Koblyuk, E. Bauer, S. Laumann, P. Rogl, J. Phys. Condens. Matter, 23 (2011) 275601.

[40] N.F. Mott, H. Jones, The theory of the properties of metals and alloys, Courier Corporation, 1958.

[41] G.-S. Joo, D.-K. Shin, I.-H. Kim, J. Electron. Mater., 44 (2015) 1383-1387.

[42] K.-H. Park, S. Lee, W.-S. Seo, I.-H. Kim, J. Korean Phys. Soc, 64 (2014) 84-88.

[43] M. Zebarjadi, J. Yang, K. Lukas, B. Kozinsky, B. Yu, M.S. Dresselhaus, C. Opeil, Z. Ren, G. Chen, J. Appl. Phys, 112 (2012) 044305.

[44] X.F. Tang, L.D. Chen, T. Goto, T. Hirai, R.Z. Yuan, J. Mater. Sci, 36 (2001) 5435-5439.

[45] G. Rogl, A. Grytsiv, E. Bauer, P. Rogl, M. Zehetbauer, Intermetallics, 18 (2010) 57-64.

[46] D.R. Thompson, C. Liu, N.D. Ellison, J.R. Salvador, M.S. Meyer, D.B. Haddad, H. Wang, W. Cai, Journal of Applied Physics, 116 (2014) 243701. 
Table 1: Average crystallite size determined using the Scherrer formula.

\begin{tabular}{ccccc}
\cline { 2 - 5 } & \multicolumn{2}{c}{ Ball milling } & \multicolumn{2}{c}{ Conventional synthesis } \\
\cline { 2 - 5 } & Single-filled & $\begin{array}{c}\text { Double- } \\
\text { filled }\end{array}$ & Single-filled & $\begin{array}{c}\text { Double- } \\
\text { filled }\end{array}$ \\
\hline Powder & $94(7) \mathrm{nm}$ & $104(5) \mathrm{nm}$ & $345(3) \mathrm{nm}$ & $221(4) \mathrm{nm}$ \\
\hline $\begin{array}{c}\text { Consolidated } \\
\text { pellet }\end{array}$ & $188(6) \mathrm{nm}$ & $156(4) \mathrm{nm}$ & $383(5) \mathrm{nm}$ & $240(3) \mathrm{nm}$ \\
\hline
\end{tabular}


Table 2. Refined parameters for $\mathrm{Ce}_{0.8} \mathrm{Fe}_{3} \mathrm{CoSb}_{12}$ and $\mathrm{Ce}_{0.5} \mathrm{Yb}_{0.5} \mathrm{Fe}_{3.25} \mathrm{Co}_{0.75} \mathrm{Sb}_{12}$, obtained using powder X-ray diffraction data (Space group: $\operatorname{Im} \overline{\mathbf{3}}$ ).

\begin{tabular}{|c|c|c|}
\hline Nominal composition & $\mathrm{Ce}_{0.8} \mathrm{Fe}_{3} \mathrm{CoSb}_{12}$ & $\mathrm{Ce}_{0.5} \mathrm{Yb}_{0.5} \mathrm{Fe}_{3.25} \mathrm{Co}_{0.75} \mathrm{Sb}_{12}$ \\
\hline Lattice parameter, $a$ / § & $9.11655(3)$ & $9.1293(1)$ \\
\hline$y(\mathbf{S b})^{\mathrm{a}}$ & $0.33654(9)$ & $0.3346(1)$ \\
\hline$z(\mathbf{S b})$ & $0.1601(1)$ & $0.1585(1)$ \\
\hline$U_{\text {iso }}(\mathbf{S b}) / \AA^{2}$ & $0.0046(3)$ & $0.0024(2)$ \\
\hline $\operatorname{SOF}(\mathrm{Sb})$ & 1 & \\
\hline$U_{\text {iso }}(\mathrm{Fe} / \mathrm{Co})^{b} / \AA^{2}$ & $0.0048(7)$ & $0.0043(3)$ \\
\hline $\operatorname{SOF}(\mathrm{Fe})$ & 0.75 & 0.8125 \\
\hline $\operatorname{SOF}(\mathrm{Co})$ & 0.25 & 0.1875 \\
\hline$U_{\text {iso }}(\mathrm{Ce})^{\mathrm{c}} / \AA^{2}$ & $0.0167(8)$ & $0.049(1)$ \\
\hline $\operatorname{SOF}(\mathrm{Ce})$ & 0.8 & 0.5 \\
\hline$U_{\text {iso }}(\mathbf{Y b})^{\mathrm{c}} / \AA^{2}$ & - & $0.049(1)$ \\
\hline $\operatorname{SOF}(\mathbf{Y b})$ & & 0.5 \\
\hline $\mathbf{R}_{\mathrm{wp}}(\%)$ & 6.50 & 5.90 \\
\hline
\end{tabular}

${ }^{\mathrm{a}} \mathrm{Sb}$ on $24 \mathrm{~g},(0, \mathrm{y}, \mathrm{z}) ;{ }^{\mathrm{b}} \mathrm{Fe} / \mathrm{Co}$ on $8 \mathrm{c}(1 / 4,1 / 4,1 / 4) ;{ }^{\mathrm{c}} \mathrm{Ce} / \mathrm{Yb}$ on $2 \mathrm{a},(0,0,0)$ 


\section{ACCEPTED MANUSCRIPT}

Table 3. Chemical composition determined using X-ray Energy Dispersive Spectroscopy (XEDS).

\begin{tabular}{ccc} 
& Single-Filled & Double-Filled \\
\hline $\begin{array}{c}\text { Pellet }- \text { Ball } \\
\text { milling }\end{array}$ & $\mathrm{Ce}_{0.8(1)} \mathrm{Fe}_{2.9(2)} \mathrm{Co}_{1.0(1)} \mathrm{Sb}_{12.0(1)}$ & $\mathrm{Ce}_{0.6(1)} \mathrm{Yb}_{0.4(1)} \mathrm{Fe}_{3.0(2)} \mathrm{Co}_{0.6(2)} \mathrm{Sb}_{12.1(2)}$ \\
\hline $\begin{array}{c}\text { Powder - } \\
\text { Conventional }\end{array}$ & $\mathrm{Ce}_{0.9(1)} \mathrm{Fe}_{2.9(2)} \mathrm{Co}_{0.8(1)} \mathrm{Sb}_{12.0(1)}$ & $\mathrm{Ce}_{0.4(1)} \mathrm{Yb}_{0.4(2)} \mathrm{Fe}_{3.2(2)} \mathrm{Co}_{0.7(2)} \mathrm{Sb}_{12.1(1)}$ \\
\hline $\begin{array}{c}\text { Pellet - } \\
\text { Conventional }\end{array}$ & $\mathrm{Ce}_{0.7(1)} \mathrm{Fe}_{2.8(2)} \mathrm{Co}_{1.0(2)} \mathrm{Sb}_{12.1(1)}$ & $\mathrm{Ce}_{0.5(1)} \mathrm{Yb}_{0.4(2)} \mathrm{Fe}_{2.9(2)} \mathrm{Co}_{0.7(1)} \mathrm{Sb}_{12.1(2)}$ \\
\hline
\end{tabular}


Table 4. Carrier concentration of the samples. $\left[x 0^{21} \mathrm{~cm}^{-3}\right]$

\begin{tabular}{cccc} 
& \multicolumn{2}{c}{ This work } & \multirow{2}{*}{ Literature [Ref] } \\
& BM & Cnvt & \\
\hline $\mathbf{C e}_{\mathbf{0 . 8}} \mathbf{F e}_{\mathbf{3}} \mathrm{CoSb}_{12}$ & 1.37 & 1.44 & $1.8 \quad[42]$ \\
\hline $\mathrm{Ce}_{\mathbf{0 . 5}} \mathbf{Y b}_{\mathbf{0 . 5}} \mathbf{F e}_{\mathbf{3 . 2 5}} \mathrm{Co}_{\mathbf{0 . 7 5}} \mathrm{Sb}_{\mathbf{1 2}}$ & 1.08 & 1.02 & $1.15 \quad[25]$ \\
\hline
\end{tabular}


Table 5. Summary of the thermoelectric properties of the synthesized single and double-filled skutterudites

\begin{tabular}{|c|c|c|c|c|c|c|c|c|}
\hline Samples & Method & $\mathbf{T}(\mathrm{K})$ & $\begin{array}{c}S \\
(\mu \mathrm{V} / K)\end{array}$ & $\rho(\mu \Omega \mathrm{m})$ & $\begin{array}{c}\mathrm{PF} \\
\left(\mathrm{mW} / \mathrm{m} \mathrm{K}^{2}\right)\end{array}$ & $\kappa(\mathrm{W} / \mathrm{m} \mathrm{K})$ & $\kappa_{L}(\mathrm{~W} / \mathrm{m} \mathrm{K})$ & ZT \\
\hline \multirow{2}{*}{$\mathrm{Ce}_{0.8} \mathrm{Fe}_{3} \mathrm{CoSb}_{12}$} & BM & $\begin{array}{c}\text { RT } \\
773\end{array}$ & $\begin{array}{c}99 \\
157\end{array}$ & $\begin{array}{c}9.29 \\
11.39\end{array}$ & $\begin{array}{l}1.06 \\
1.85\end{array}$ & $\begin{array}{l}2.01 \\
2.1\end{array}$ & $\begin{array}{l}1.21 \\
0.44\end{array}$ & $\begin{array}{l}0.16 \\
0.68\end{array}$ \\
\hline & Cnvt & $\begin{array}{l}\text { RT } \\
773\end{array}$ & $\begin{array}{c}88 \\
139\end{array}$ & $\begin{array}{l}7.95 \\
9.69\end{array}$ & $\begin{array}{l}0.97 \\
1.99\end{array}$ & $\begin{array}{l}2.1 \\
2.26 \\
2.51\end{array}$ & $\begin{array}{l}1.33 \\
0.56\end{array}$ & $\begin{array}{l}0.13 \\
0.61\end{array}$ \\
\hline \multirow[b]{2}{*}{$\mathrm{Ce}_{0.5} \mathrm{Yb}_{0.5} \mathrm{Fe}_{3.25} \mathrm{Co}_{0.75} \mathrm{Sb}_{12}$} & BM & $\begin{array}{l}\text { RT } \\
773\end{array}$ & $\begin{array}{l}95 \\
155\end{array}$ & $\begin{array}{l}6.87 \\
8.79\end{array}$ & $\begin{array}{l}1.31 \\
2.73\end{array}$ & $\begin{array}{l}2.81 \\
2.44\end{array}$ & $\begin{array}{l}0.65 \\
0.29\end{array}$ & $\begin{array}{l}0.01 \\
0.22 \\
0.86\end{array}$ \\
\hline & Cnvt & $\begin{array}{c}\text { RT } \\
773\end{array}$ & $\begin{array}{c}153 \\
98 \\
162\end{array}$ & $\begin{array}{c}0.15 \\
7.26 \\
10.28\end{array}$ & $\begin{array}{l}1.32 \\
2.55\end{array}$ & $\begin{array}{l}2.44 \\
2.19 \\
2.41\end{array}$ & $\begin{array}{l}1.17 \\
0.54 \\
\end{array}$ & $\begin{array}{l}0.18 \\
0.82\end{array}$ \\
\hline
\end{tabular}




\section{Figure captions}

Figure 1. Polyhedral representation of the filled skutterudite structure, illustrating the void space in which filler atoms reside.

Figure 2 Powder $\mathrm{X}$ ray diffraction patterns of the as-prepared ball-milled samples, recorded under Kapton foil to avoid reaction with air, and the same samples after consolidation by hot pressing.

Figure 3 Final observed (red dotted line), refined (black solid line) and difference (lower blue line) profiles from Rietveld refinement using powder X-ray diffraction data for $\mathrm{Ce}_{0.8} \mathrm{Fe}_{3} \mathrm{CoSb}_{12}$ and $\mathrm{Ce}_{0.5} \mathrm{Yb}_{0.5} \mathrm{Fe}_{3.25} \mathrm{Co}_{0.75} \mathrm{Sb}_{12}$. Markers indicate the reflection positions for the skutterudite phase.

Figure 4 SEM micrographs of hot-pressed pellets: a) $\mathrm{Ce}_{0.8} \mathrm{Fe}_{3} \mathrm{CoSb}_{12}-$ ball milling synthesis, b) $\mathrm{Ce}_{0.8} \mathrm{Fe}_{3} \mathrm{CoSb}_{12}-$ conventional synthesis, c) $\mathrm{Ce}_{0.5} \mathrm{Yb}_{0.5} \mathrm{Fe}_{3.25} \mathrm{Co}_{0.75} \mathrm{Sb}_{12} \quad$ - ball milling synthesis, d) $\mathrm{Ce}_{0.5} \mathrm{Yb}_{0.5} \mathrm{Fe}_{3.25} \mathrm{Co}_{0.75} \mathrm{Sb}_{12}$ - conventional synthesis.

Figure 5 Thermogravimetric analysis (TGA) for $\mathrm{Ce}_{0.8} \mathrm{Fe}_{3} \mathrm{CoSb}_{12}$ and $\mathrm{Ce}_{0.5} \mathrm{Yb}_{0.5} \mathrm{Fe}_{3.25} \mathrm{Co}_{0.75} \mathrm{Sb}_{12}$ samples prepared by both ball-milling and conventional high-temperature synthesis.

Figure 6 Electrical transport properties of $\mathrm{Ce}_{0.8} \mathrm{Fe}_{3} \mathrm{CoSb}_{12}$ and $\mathrm{Ce}_{0.5} \mathrm{Yb}_{0.5} \mathrm{Fe}_{3.25} \mathrm{Co}_{0.75} \mathrm{Sb}_{12}$ as a function of temperature: Seebeck coefficient (top), electrical resistivity (middle) and power factor (bottom).

Figure 7 Thermal conductivity ( $\kappa$ ) of $\mathrm{Ce}_{0.8} \mathrm{Fe}_{3} \mathrm{CoSb}_{12}$ and $\mathrm{Ce}_{0.5} \mathrm{Yb}_{0.5} \mathrm{Fe}_{3.25} \mathrm{Co}_{0.75} \mathrm{Sb}_{12}$ as a function of temperature: total (top), lattice thermal conductivity $\left(\kappa_{\mathrm{L}}\right)$ (middle) and electronic thermal conductivity $\left(\kappa_{\mathrm{e}}\right)$ (bottom).

Figure 8 Temperature dependence of the figure of merit, ZT, of the p-type skutterudites prepared by ball milling compared with materials prepared by conventional synthesis. 


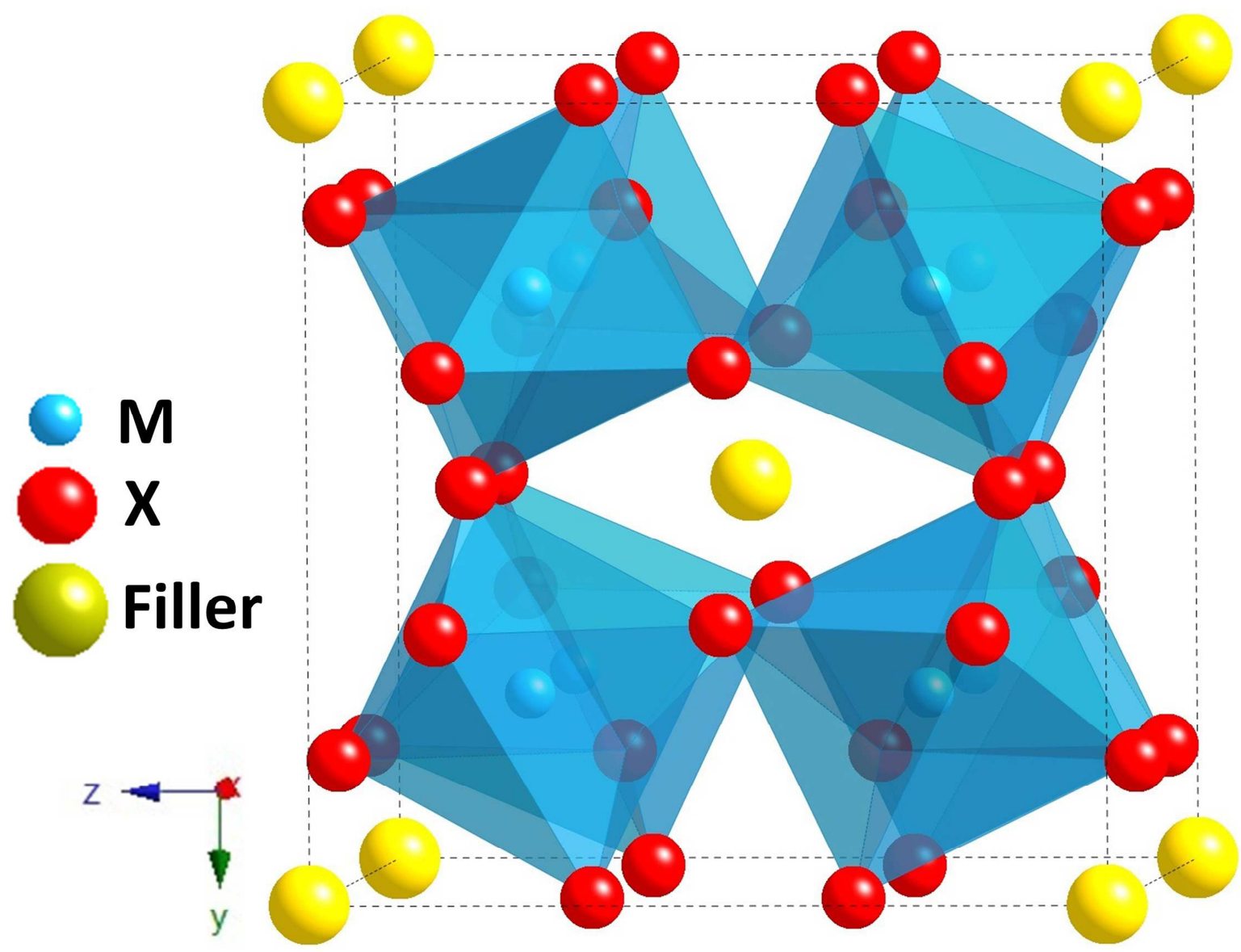




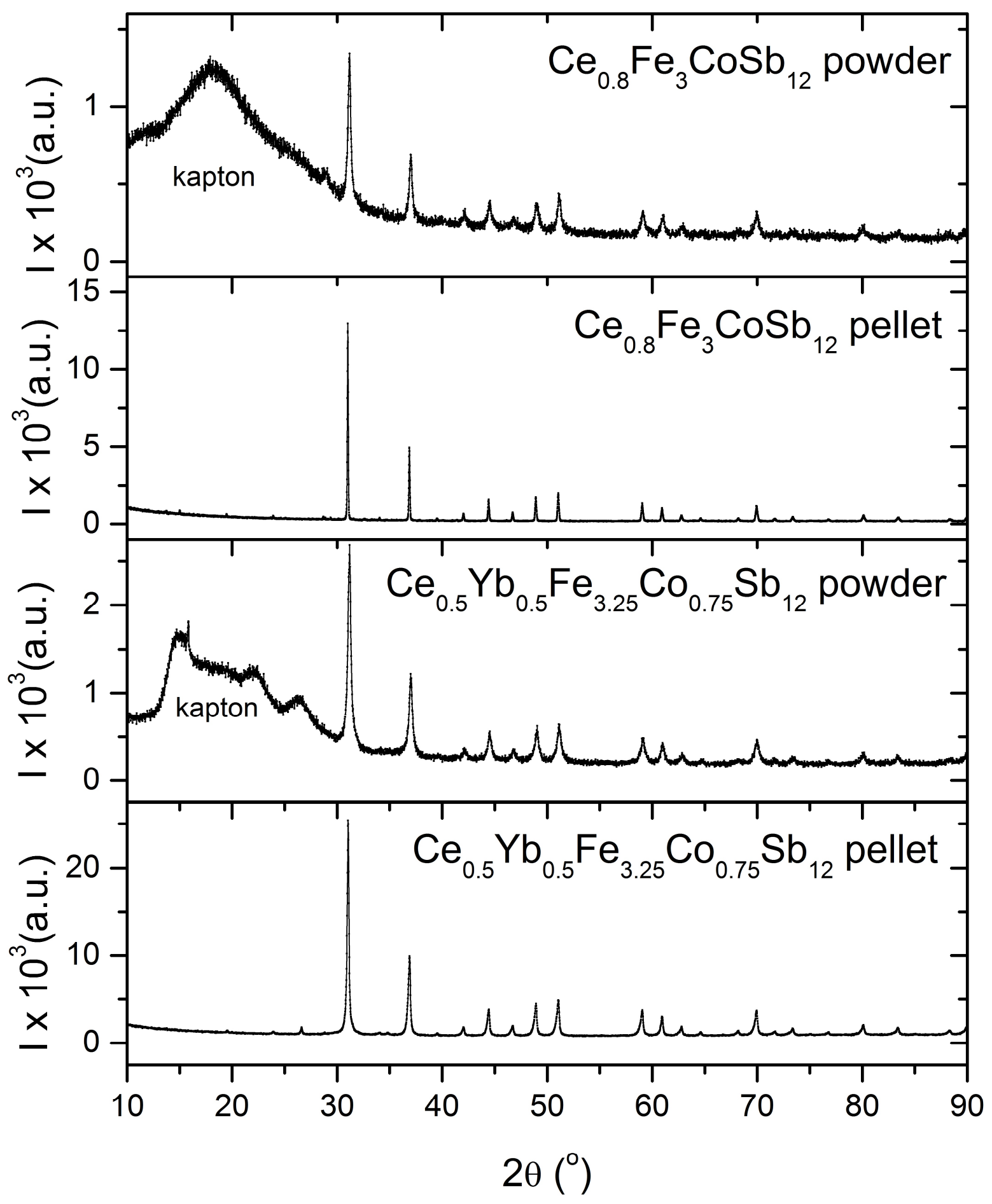




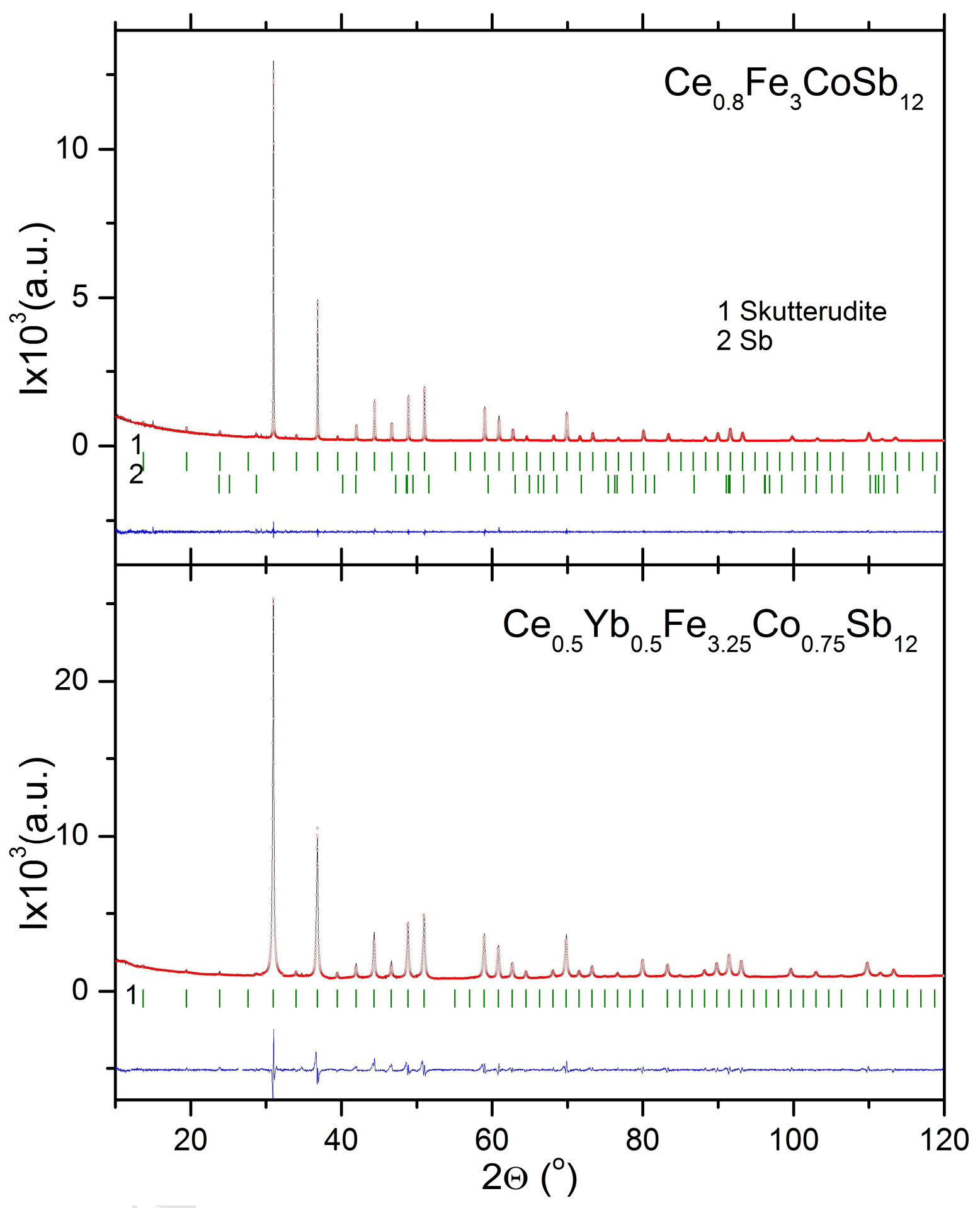


(a)

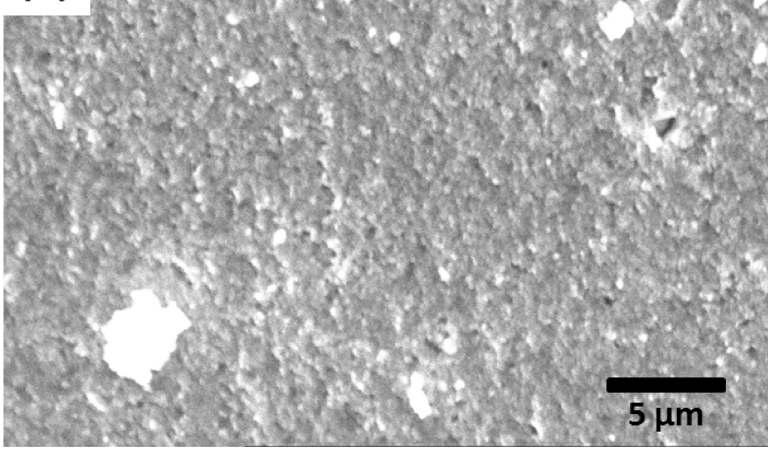

(c)

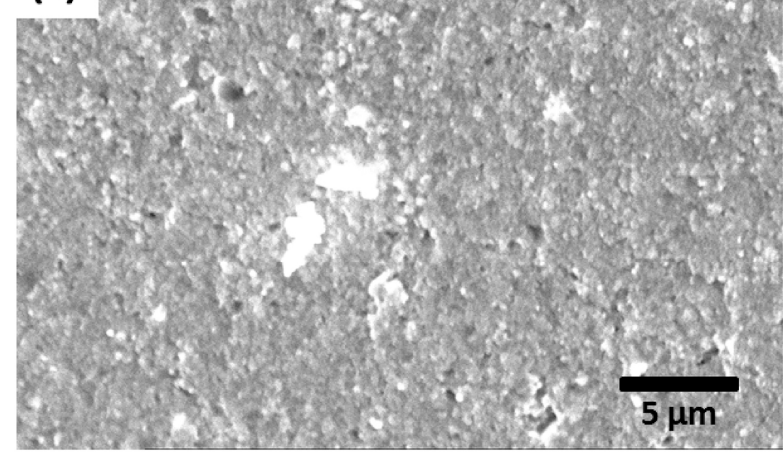

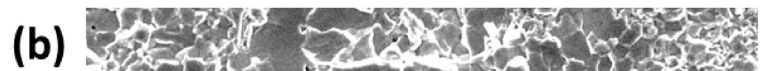
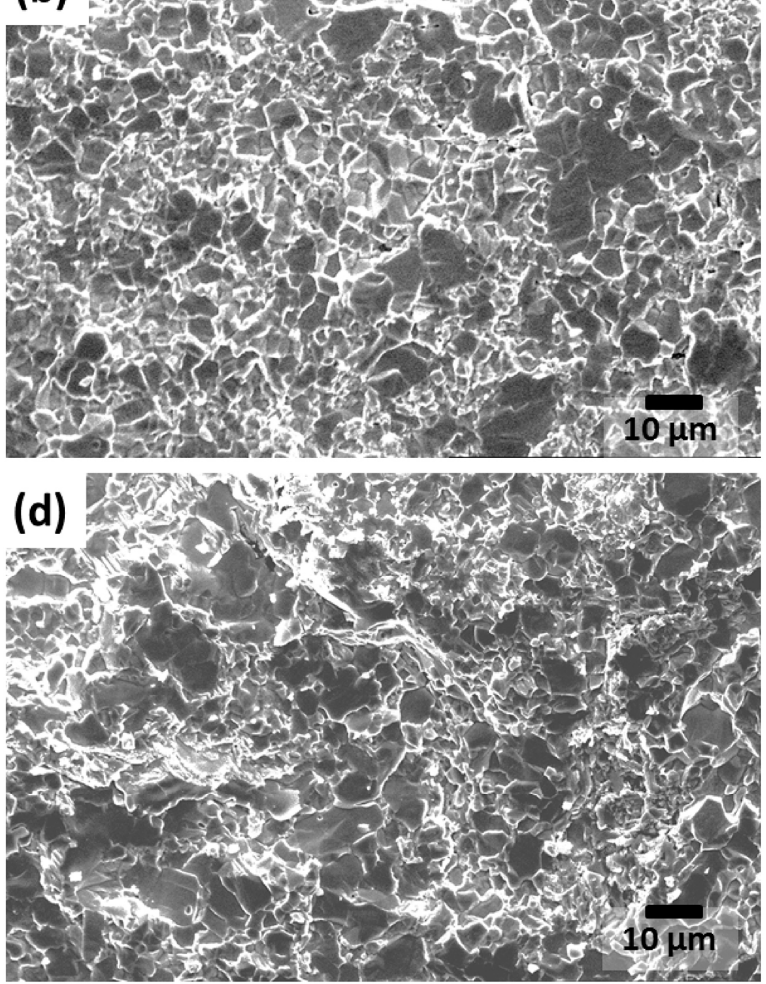


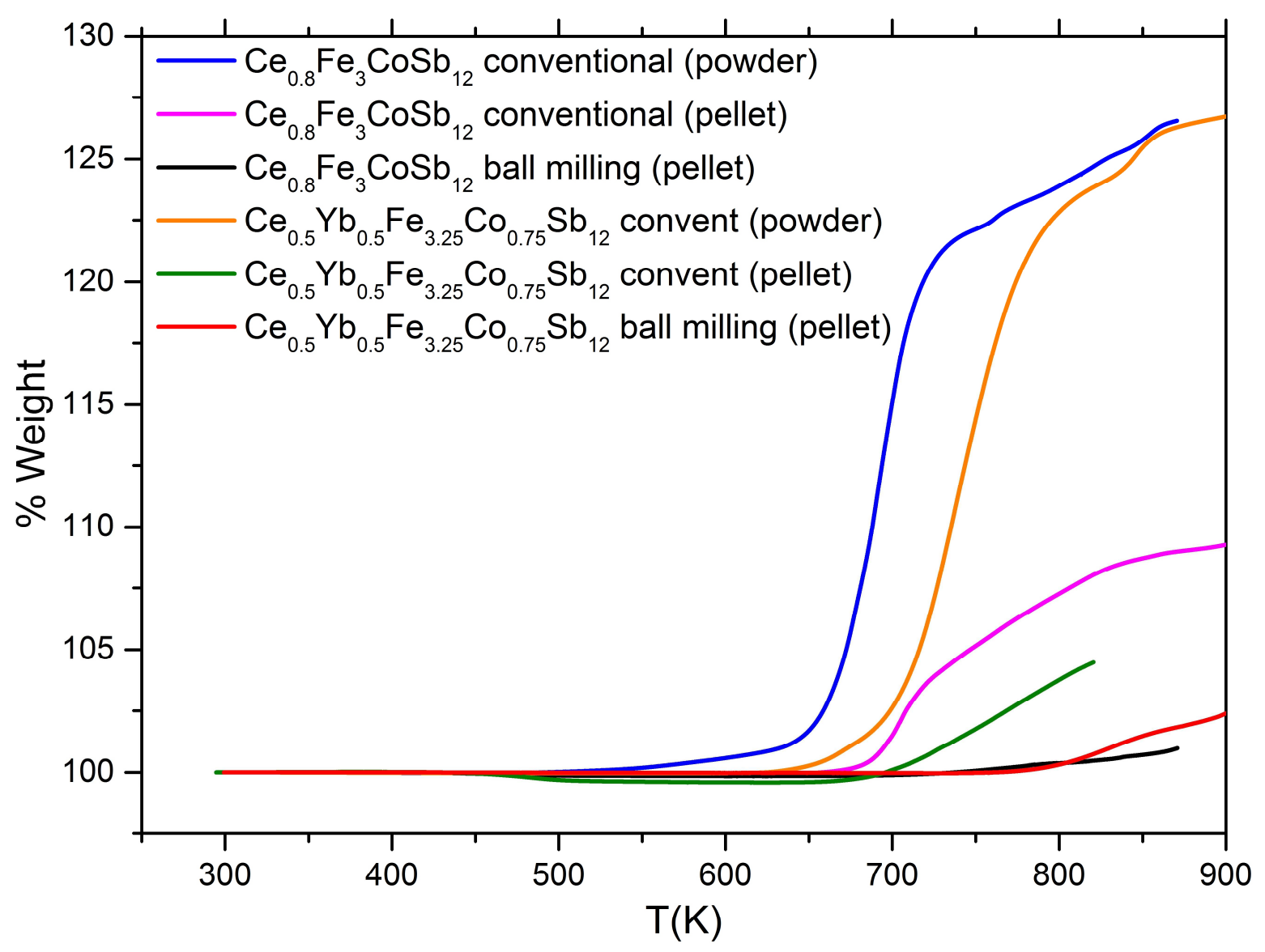




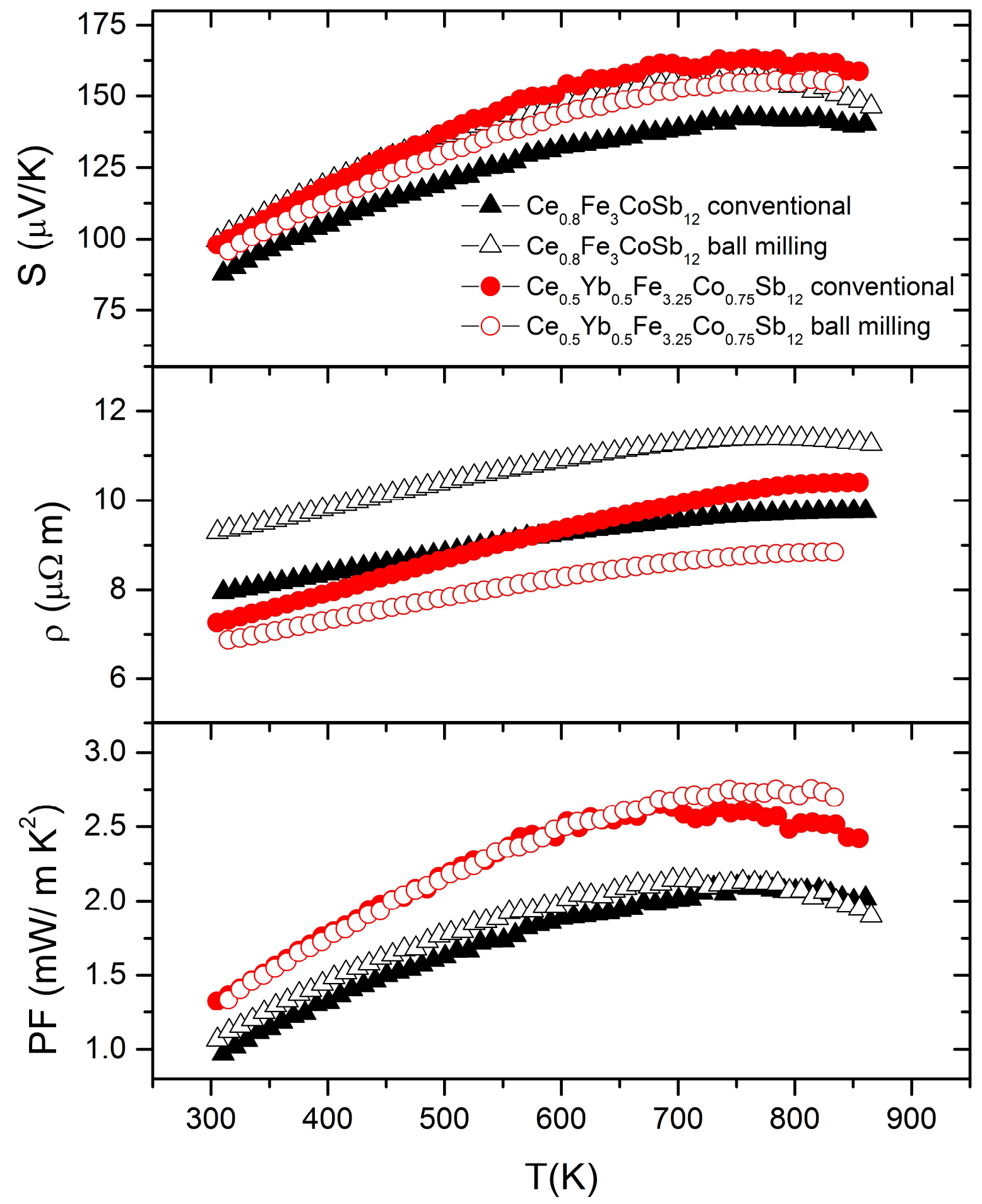




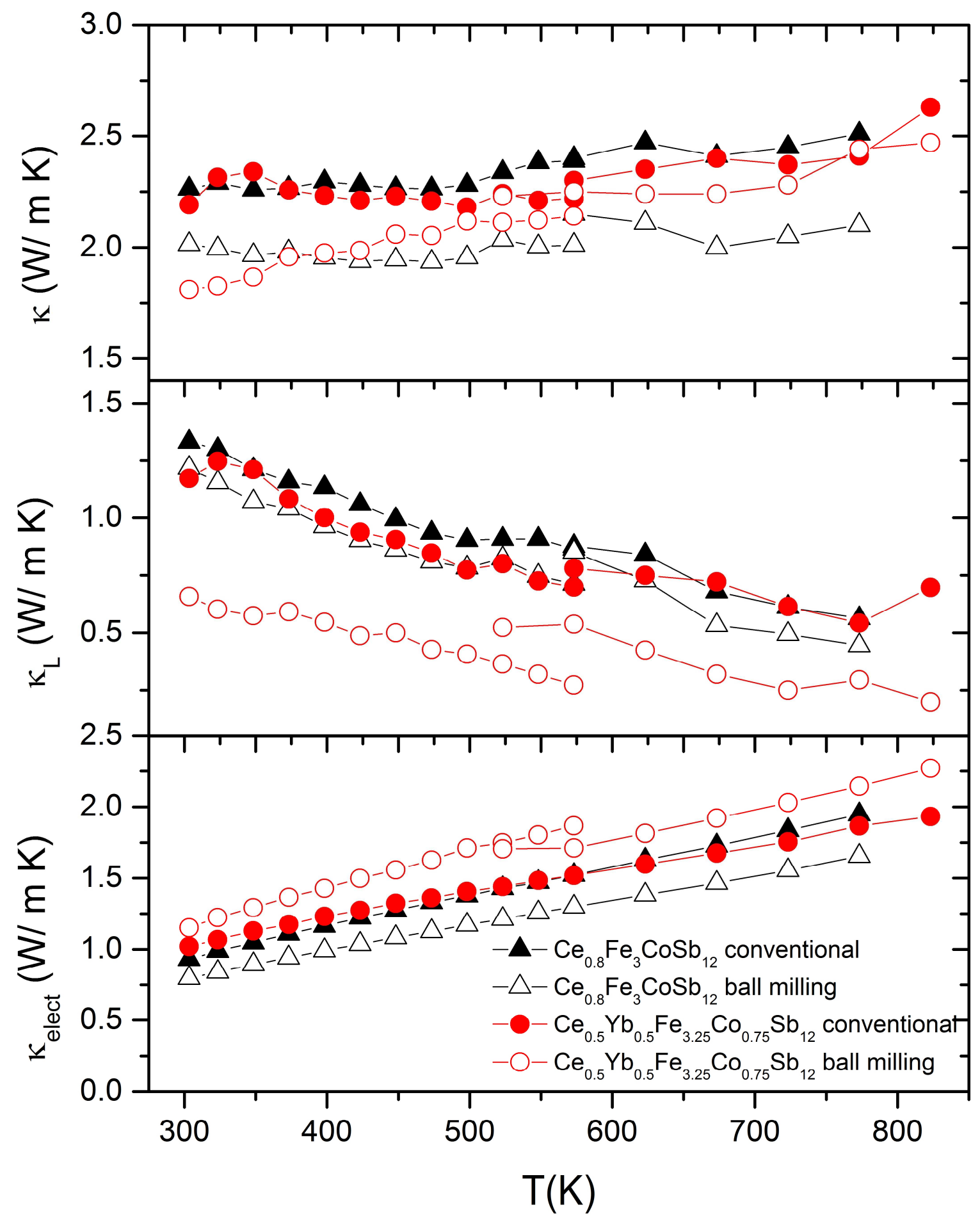




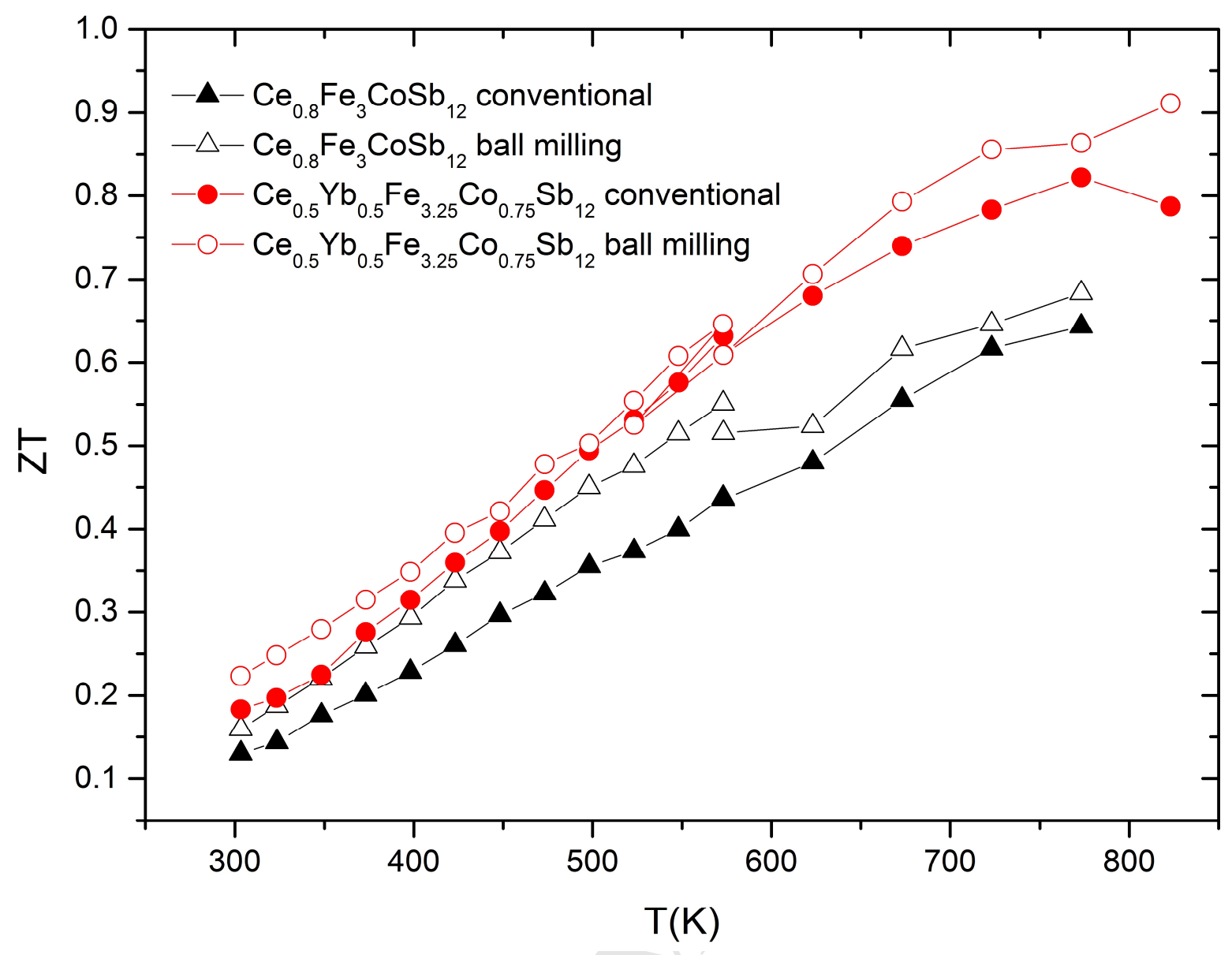




\section{Highlights}

- Large samples of p-type filled skutterudites produced by ball milling.

- TE performance matches or exceeds that of conventionally-prepared materials.

- Reduced thermal conductivity associated with the reduction in grain-size.

- Consolidated ball-milled materials are more resistant to oxidation. 